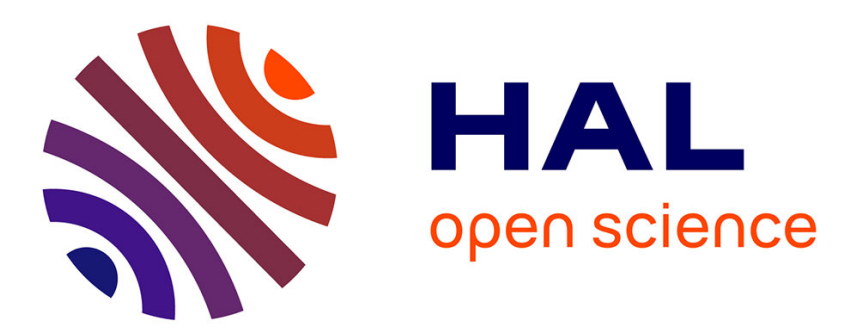

\title{
Impact of environmental based effects on SHM strategies
} Matthias Baessler, Md Delwar Hossain Bhuyan, Falk Hille, Eva Viefhues, Michael Döhler, Laurent Mevel

\section{To cite this version:}

Matthias Baessler, Md Delwar Hossain Bhuyan, Falk Hille, Eva Viefhues, Michael Döhler, et al.. Impact of environmental based effects on SHM strategies. SEMC 2019 - 7th International Conference on Structural Engineering, Mechanics and Computation, Sep 2019, Cape Town, South Africa. pp.1-6. hal-02290909

\section{HAL Id: hal-02290909 \\ https://hal.inria.fr/hal-02290909}

Submitted on 18 Sep 2019

HAL is a multi-disciplinary open access archive for the deposit and dissemination of scientific research documents, whether they are published or not. The documents may come from teaching and research institutions in France or abroad, or from public or private research centers.
L'archive ouverte pluridisciplinaire HAL, est destinée au dépôt et à la diffusion de documents scientifiques de niveau recherche, publiés ou non, émanant des établissements d'enseignement et de recherche français ou étrangers, des laboratoires publics ou privés. 


\title{
Impact of environmental based effects on SHM strategies
}

\author{
M. Baeßler, D. Bhuyan, F. Hille \& E. Viefhues \\ Bundesanstalt für Materialforschung und -prüfung, Berlin, Germany \\ M. Döhler \& L. Mevel \\ Inria, Ifsttar, Univ. Rennes, Rennes, France
}

\begin{abstract}
Environmental based perturbations influence significantly the ability to identify structural damage in Structural Health Monitoring. Strategies are needed to classify such effects and consider them appropriately in SHM. It has to be considered if seasonal effects just mask the structural response or if temperature itself correlates to a weakening of the structure. Various methods have been developed and analyzed to separate environmental based effects from damage induced changes in the measures. Generally, two main approaches have emerged from research activity in this fields: (a) statistics-based tools analyzing patterns in the data or in computed parameters and (b) methods, utilizing the structural model of the bridge considering environmental as well as damage-based changes of stiffness values. With the background of increasing affordability of sensing and computing technology, effort should be made to increase sensitivity, reliability and robustness of procedures, separating environmental from damage caused changes in SHM measures. The contribution describes an attempt to evaluate both general strategies, their advantages and drawbacks. In addition, two vibration monitoring procedures are introduced, allowing for temperature-based perturbations of the monitoring data.
\end{abstract}

\section{INTRODUCTION}

In Structural Health Monitoring (SHM) of civil engineering structures, the information value of the measured data is often limited by the effects of environmental characteristics. In this context, the structure's temperature driving parameters air temperature and solar radiation have the most significant influence.

Especially SHM methods for the identification of structural damage are prone to false alarms, when temperature affects the static and dynamic behavior in different ways or simply influence the measurement. In general, temperature-based effects on features indicating SHM damage are more significant than local structural damage in an early stage (Farrar et al., 1997, Peeters and De Roeck, 2001, Rohrmann et al., 2000). For that reason, the environmental variability is a crucial issue for the practicability of SHM.

To eliminate the masking effect of temperaturebased variations on damage detection and localization procedures in SHM different approaches have been proposed in the last decades by the research community. Generally, two different approaches are pursued, first utilizing physical models to compute the effect of varying temperature on the structural response and second, statistical models to filter out the temperature induced perturbations on the monitoring data.

Physical model-based approaches are closely connected with the structural circumstances and described in several publications. Meruane and Heylen (2012) developed a physical model-based damage detection procedure which employs a genetic algorithm for optimization to solve the inverse problem. They successfully tested the method on simulated and experimentally generated data of the steelconcrete composite I-40 bridge.

On the other hand, statistical methods are solely based on measurement data without using any geometrical or material information describing the behavior of the observed structure. To eliminate the effect of varying environmental perturbation in signals of damage indicating features, the data is processed utilizing statistical models.

At present, several methods utilizing different statistical models are developed and adapted by the SHM community. Generally, two different approaches can be distinguished, those including and those not including the measured environmental parameters into the statistical analysis. A general summary including simple regression based methods is given in (Baeßler and Hille, 2018).

In this paper an overview of the different physical as well as statistical model-based approaches is given, and two statistical algorithms are described. As a basis, firstly the influence of the several mechanisms of a relation between the temperature field in a structure and its response are addressed. Thereafter, the paper introduces physical model-based approaches for 
different structural issues. Based on simulated measurement data, the allowance of temperature-based variations on two subspace-based indicators for first, damage detection and second, damage localization is demonstrated in the paper. Namely, the robustness of the Stochastic Subspace-based Damage Detection (SSDD) (Döhler et al., 2014, Viefhues et al., 2017) and of the Statistical Stochastic Dynamic Damage Locating Vector method (S-SDDLV) (Bhuyan et al., 2017, Döhler et al., 2013) on varying temperature is increased by statistical model-based analysis.

\section{PHYSICAL BEHAVIOR}

\subsection{Influences on the temperature field in bridge structures}

To include the effect of temperature loading to the computation of structural responses it is necessary to account for the influencing thermal processes and principles. For determination of the temperature field in a structure, the heat transfer on the structures surfaces together with the boundary conditions by the surrounding environment is decisive. Heat transfer describes the exchange of thermal energy between the physical systems and consists out of the three general parts: conduction, convection and radiation. The heat transfer of a structure exposed to the natural atmosphere is dependent on the following influences: ambient air temperature, wind speed, rain, ice, humidity, global radiation of the sun (direct and diffuse radiation), reflection of the global radiation of the sun, atmospheric radiation, radiation of the environment and reflection of the radiation, heat radiation of the component as well as evaporation and condensation.

To determine the temperature field of a structure, the knowledge of the measured meteorological data in its characteristic course of the day and of the year as well as data of the thermo-physical material characteristics such as emission coefficients, thermal conductivity or specific heat capacity are necessary.

But even accounting for the general thermal parameters in the temperature field computation, especially for comparative studies one should be aware, that most of the processes are transient and thus two equal states of temperature distribution on a bridge structure are hardly feasible.

\subsection{Thermal structural behavior}

Table 1 summarizes the influence of seasonal changes on structural members with respect to its physical origin. (a) describes the well-known fact that bridges with asphalt layer react far stiffer in cold season than in summer. In general, if the material behavior of a homogeneous region itself is temperature-dependent, additional considerations are necessary to assess the effect of the temperature field. (b) addresses the seasonal impact on concrete structures truly affecting the capacity (c) Gonzales et al. (2013) investigated a ballasted concrete railway bridge in north Sweden and proved large dependencies of the dynamic response by the temperature variations in the ballast and the ground, especially during frost. (d) and (f) give examples for the impact of temperature on the support conditions. Finally, there is a possibility that slender members are affected by stress softening (or stiffening) (e).

Table 1. Temperature influence on structural components.

a) Asphalt layer: strong dependency of stiffness on temperature

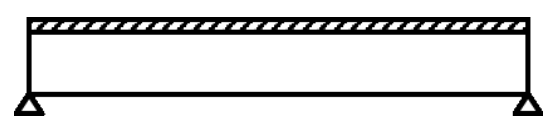

b) Reinforced and prestressed concrete: stiffness can vary for $\mathrm{E}$ depends on temperature and humidity and cracks or coupling joints might open with temperature

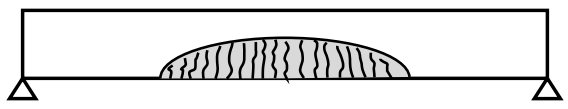

c) Ballasted Track: stiffness changes with temperature

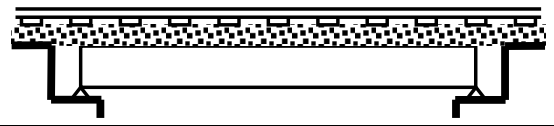

d) Structure soil interaction: stiffness at columns and at abutments can be frost dependent

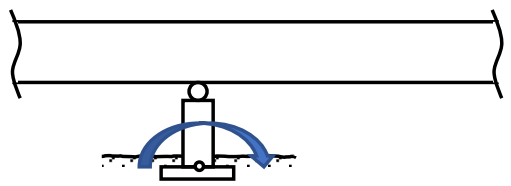

e) Axial forces: for constrained slender structures, axial forces and vibration modes are coupled

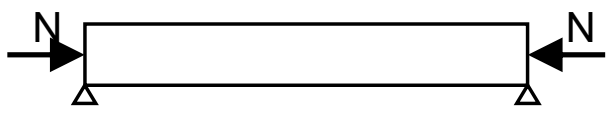

f) Bearings: typical bearing materials can behave temperature dependent

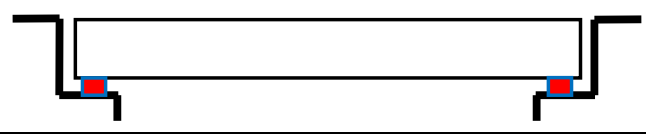

\section{METHODS BASED ON PHYSICAL MODELS}

\subsection{Requirements on physical models}

For design and structural assessment physical models are a relevant precondition to relate the structural response to a meaningful statement on the structure's behavior. Physical models verified from SHM results can be either used for the assessment of bearing capacity or the structures dynamic behavior:

\section{- Assessment of load bearing capacity}

The aim of Structural Health Monitoring (SHM) is the measurement-based assessment of the load-bearing capacity of a structure. 
In detail that means to detect damage, to identify changes in load bearing capacity and to determine the safety level. It is essential to correctly evaluate temperature influences. Generally, the main challenge of a global state monitoring is the provision of an adequate sensitivity of the damage detection methodology for essential damage scenarios. Damages in their initial stage on robust structures as reinforced and prestressed bridges are normally not activated by existing traffic load. Accordingly, no changes in the stiffness ratios are detectable, and thus the damage cannot be detected by means of a measurement of global structural parameters based on the dynamic response. This situation must always be considered in planning monitoring systems for bridge structures.

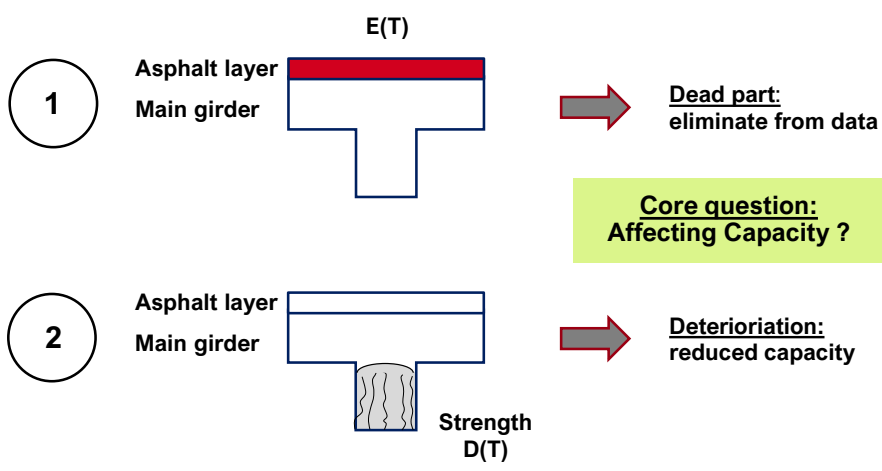

Figure 1. Stiffness changes with different relevance for structural safety.

For a physical model-based monitoring of the structural state, a model in high quality is required to provide a connection between system identification and monitoring variables on the one hand and the related load-bearing evaluation on the other hand. For a typical reinforced concrete cross section, this also means that temperature dependent changes in the load bearing behavior must be assessed correctly. Figure 1 shows two cases: In case (1), the structure reacts stiffer due to the carrying effect of the asphalt layer. In terms of safety evaluation, however, this stiffness share is not taken into account. In case (2), the change in the load bearing behavior during crack formation, for example from temperature dependent constraints and inherent stresses, is shown. In the sense of safety assessment, this leads to a reduction of the load bearing capacity in the sense of stability assessment. Those distinctions are elementary for an evaluation. (Baeßler and Hille, 2018)

\section{- System identification for dynamic verification}

Measurements are carried out to identify a dynamic structural behavior. In the case of a dynamic structural analysis, there is no verification to the safer side, the dynamic behavior of the structure must be considered in its actual limits to take account of resonance effects, for example to verify the dynamic behavior of railway bridges during train crossing. Particularly, fatigue and the limitation of maximum acceleration amplitudes of the bridge deck are considerably dependent on modal parameters of the bridge structure.

\subsection{Physical Testing}

Data on temperature dependent physical behavior of building materials is rare [see e.g. (Eisenmann et al., 1969, Simonsen et al., 2002, Welsch, 1984). The focus of interest is often restricted to extreme conditions like fire or severe frost conditions. A current research interest is a better understanding of the behavior at "normal" seasonal conditions. Furthermore the structural behavior is not universal (variability e.g. due to specific mixtures, fabrication, age). This leads to a second focus on the determination of site-specific characteristic values. For the various open questions a large climate chamber has been developed for further investigation (Figure 2).

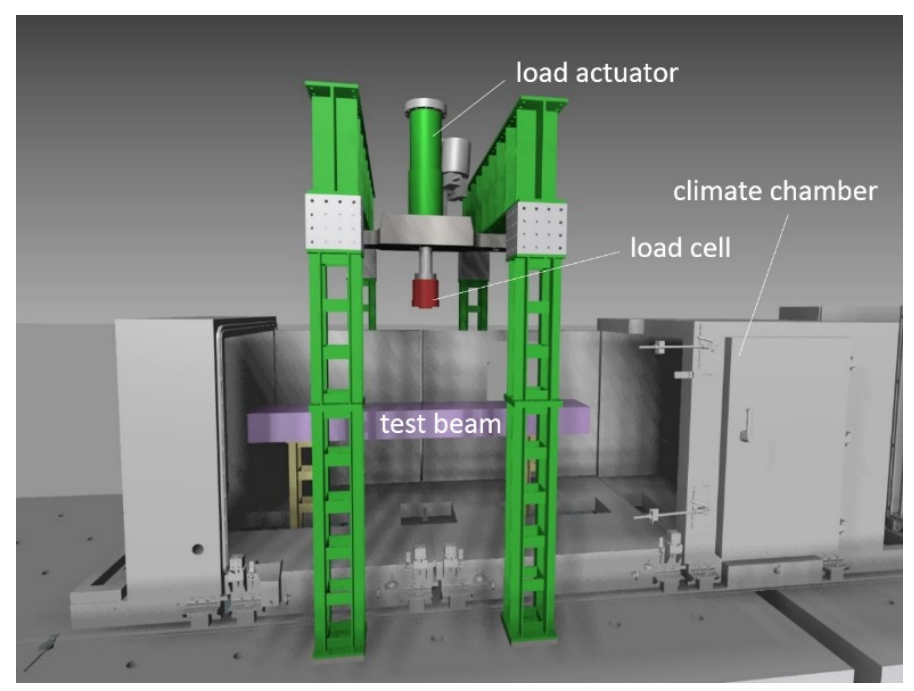

Figure 2. Climate chamber [temperature $-40^{\circ} \mathrm{C}$ up to $60^{\circ} \mathrm{C}$; variable humidity $10 \%$ to $80 \%$ ].

In that respect the scope of research is focused on the following topics:

- Material level: characteristic values for stiffness and damping in correlation to temp. and humidity

- Full specimen level: constraints and bonding and its impact on fracturing as well specific contact nonlinearities

- Testing methods: Role of excitation; stationary or moving load.

- Evaluation of site-specific properties

- Damage detection and localization

- Model updating for changing structural conditions although it has to be stretched, that research is ongoing.

\section{STATISTICAL METHODS UTILIZING VIBRATION MONITORING}

In addition to simple statistical tools using linear regression models for removing effects of environmental variations on the monitoring data we utilize 
statistical vibration-based damage diagnosis methods which provide the rejection of environmental influences as method inherent feature. On the common base of the stochastic subspace-related system description two different methods for damage diagnosis are introduced, both allowing for environmental perturbations.

\subsection{Damage detection allowing for environmental perturbation}

Statistical approaches are promising when it comes to damage diagnosis using temperature afflicted vibration data. In the stochastic subspace-based damage detection (SSDD) the careful choice of an adequate reference system enables the formulation of algorithms robust to temperature variation.

The basic idea of the method is to exploit a Hankel matrix $\mathcal{H}$, which contains the cross-covariances of the output signal at different time steps in the reference state. For its left null space $\mathrm{S}$ it holds $S^{T} \mathcal{H}=0$. By definition, $\mathcal{H}$ depends on the system matrices of the state-space representation of the dynamical system, namely the state transition matrix $A$ and the observation matrix $C$. Therefore, changes in the dynamical system will result in a change of $\mathcal{H}$. In the monitoring state, $\mathrm{S}$ is confronted to $\mathcal{H}$ in a data-based residual vector

$\zeta=\sqrt{N} \operatorname{vec}\left(S^{T} \mathcal{H}\right)$

$\mathcal{H}$ is built from data in the monitoring state. The value of the residual will be different from 0 , if $\mathrm{H}$ has changed significantly. This is tested statistically in a hypothesis testing framework. From test values in the undamaged case a threshold is computed. If the test value in the monitoring state exceeds the threshold a damage is detected.

In the context of temperature rejection, the challenge is, to choose a good reference system, to enable a proper threshold, which enables high probability of detection but few false alarms. Three approaches will be introduced shortly.

A simple temperature rejection approach is proposed in (Balmès et al., 2008). The reference null space and the residual covariance for the hypothesis tests are computed on an averaged Hankel matrix in the reference state. The averaged Hankel matrix is obtained from a big data set $\bar{Y}=\left[\begin{array}{llll}Y_{1} & Y_{2} & \cdots & Y_{m}\end{array}\right]$ merged from $Y_{j}=\left[\begin{array}{llll}y_{1, j} & y_{2, j} & \cdots & y_{N, j}\end{array}\right]$ at $j=1, \ldots, m$ different reference temperatures $T_{j}$. The whole test can be performed without any information about the reference temperatures.

If temperature measurement information is taken into account, a reference system can be computed piecewise for a specific temperature range, as proposed e.g. in (Fritzen et al., 2003). The reference null space matrices $S_{j}$ and corresponding covariances $\Sigma_{\mathcal{H}_{j}}$ are estimated on reference data $Y_{j}$ at a reference temperature $T_{j}$. In the monitoring state, the nearest reference null space with respect to the current testing temperature is used for the damage diagnosis.

In another approach presented in (Viefhues et al., 2019) the reference null space and the residual covariance are based on an interpolation step. An interpolated Hankel matrix

$$
\underline{\mathcal{H}}(T)=\sum_{j=1}^{m} \rho_{j}^{2}(T) \mathcal{H}_{j}
$$

for the testing temperature $T$ with bell-shaped weighting functions $\rho_{j}(T)$ leads to the null space matrix $S(T)$ and the corresponding covariance of the interpolated Hankel matrix

$$
\underline{\Sigma}_{\mathcal{H}}(T)=\sum_{j=1}^{m} \rho_{j}^{4}(T) \Sigma_{\mathcal{H}_{j}} .
$$

Figure 3 shows the undamaged and damaged test values at different testing temperatures for the three temperature rejection approaches. For an 8-mass-spring damper the temperature variations were simulated as stiffness increasing (lower temperatures) or reduction (higher temperatures). 5 reference temperatures are considered. A global damage is modeled as stiffness reduction of $2 \%$ at every element.
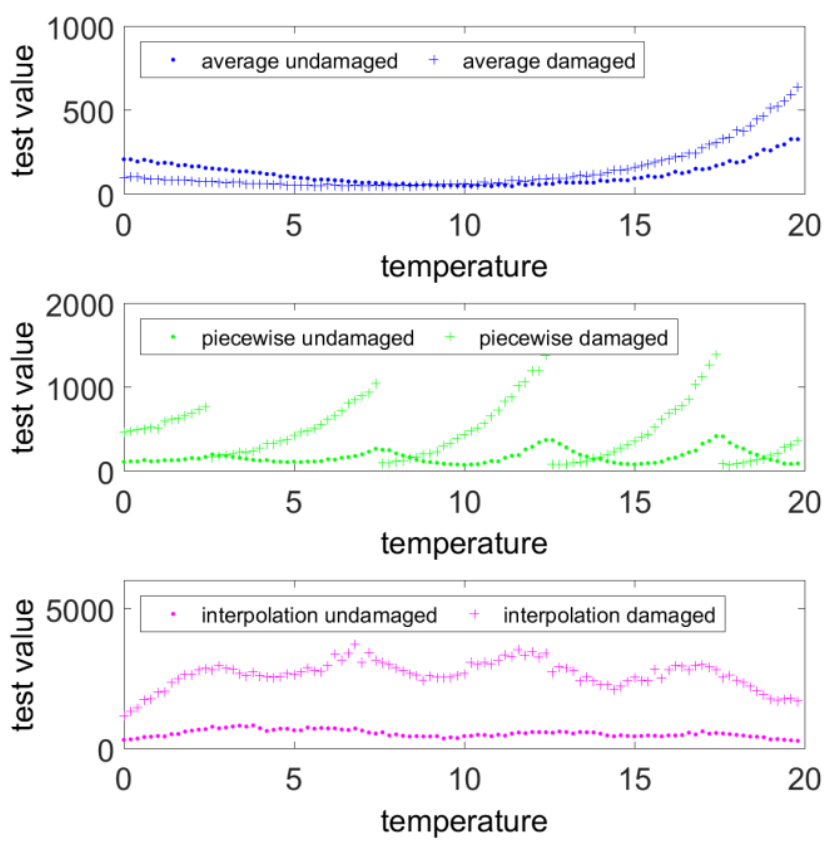

Figure 3. Test values in undamaged and damaged case for different temperature rejection approaches.

With the average and the piecewise method, it will be impossible to find a good threshold for damage detection, as the test values in the damaged state sometimes exceed the undamaged values and sometimes fall below them. The approaches are not able to decide if temperature or damage affected the stiffness of the system, as they do not consider the right reference system for the specific testing temperature. The 
interpolation method, however, can provide a proper reference system for each testing temperature. This results in a clear shift of the test values in case of damage and thus enables a definition of a threshold for damage detection.

\subsection{Damage Localization allowing for environmental perturbation}

In a second development, the statistical extension of the Stochastic Dynamic Damage Locating Vector (SSDDLV) approach has been utilized (Bhuyan et al., 2017, Döhler et al., 2013). The SDDLV is an outputonly damage localization method based on both a finite element model of a structure and modal parameters estimated from output-only measurements in the reference and damaged states. A statistical version of the approach takes into account the inherent uncertainty due to noisy measurement data. Therefore, the effect of temperature variations on the performance of the method is analyzed in a model-based approach using a finite element model with temperature dependent parameters. For robust damage localization, the temperature effect on the identified modal parameters in the damaged state is rejected by sensitivity analysis.

\subsubsection{Numerical application: Beam model}

The method is applied on a simulated structure as shown in Figure 4 with temperature dependent parameters (Gautier et al., 2018). The structure is modeled with 4 main beam elements of length $1 \mathrm{~m}$. The mass density, Young modulus and Poisson ratio are $7800 \mathrm{~kg} / \mathrm{m} 3,70 \mathrm{GPa}\left(\right.$ at $\left.20^{\circ} \mathrm{C}\right)$ and 0.33 , respectively.

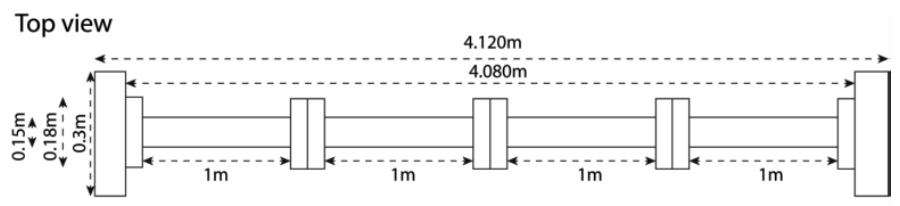

Figure 4. 3D Model with 30 beam elements.

In the Finite Element (FE) model, each main beam element is discretized into 5 small elements and hence, the total number of elements is 30 , and the number of degrees of freedom of the structure is 180 . Damping is defined such that the damping ratio of all modes is $0.2 \%$. Note that the damaged position is modeled at elements $12-14$ (1.45 m from left end) by decreasing $30 \%$ stiffness loss. For the damaged and undamaged states, the acceleration data length for each simulated set is $\mathrm{N}=100,000$, generated from collocated white noise excitation using four sensors in the Y-direction at $0.43 \mathrm{~m}, 1.49 \mathrm{~m}, 2.49 \mathrm{~m}$, and 3.47 $\mathrm{m}$ from the left support end with a sampling frequency of $2000 \mathrm{~Hz}$, and $5 \%$ white noise was added to the output data.

After applying a heat source at element 17, the temperature field is computed at the elements of the finite element model. Their stiffness is then computed from the obtained temperatures and used for the data simulation for different magnitudes of the heat flux. Moreover, Figure 5 shows that how the first modal frequency is varying in terms of increasing heat flux for both healthy and damaged states.

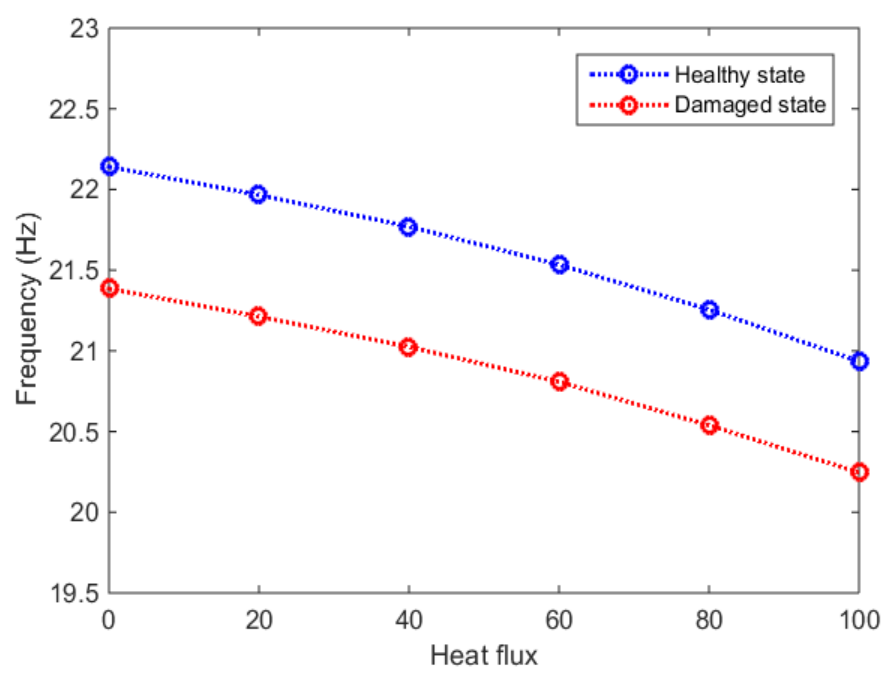

Figure 5. Temperature effect on the first modal frequency for both healthy and damaged states. Damaged at elements 12, 13 and 14 (30\% stiffness loss).

\subsubsection{Performance evaluation of damage localiza- tion with and without temperature rejection}

To analyze the performance of the SDDLV method under temperature variation, the success rate (or probability) of damage localization is evaluated for 100 sets of simulated measurement data in a Monte Carlo experiment. In order to make decision if an element is potentially damaged or not, the $\chi_{t}^{2}$ value is tested for each structural element. For each Monte Carlo realization, damage localization is seen as successful when the smallest $\chi_{t}^{2}$ value among all elements is indeed at the damaged element, and the success rate is the percentage of realizations for which the $\chi_{t}^{2}$ value at the damaged element is the smallest $\chi_{t}^{2}$ value. The success rate depends on the chosen value for Laplace variable $\mathrm{s}$ and serves as the performance indicator for the method. Notice that the generation of several datasets allows the evaluation of the success rate, while usually only one dataset is available.

In Figure 6, the mean of the success rates of damage localization (e.g. both estimated stress and its statistical evaluation) for values of Laplace variable $\mathrm{s}$ with $\operatorname{Im}(s)=100,150, \ldots, 1300$ are shown in dependence of the heat flux in the damaged state with and without the temperature rejection approach. Without using rejecting the temperature effect, it is seen that the success rate decreases when the heat flux increases, since no heat flux is present in the healthy state. The performance of the localization results is significantly improved by using the temperature rejection strategy. Considering temperature rejection, 
figure shows that the success rate is constantly high and nearly independent of the heat flux.

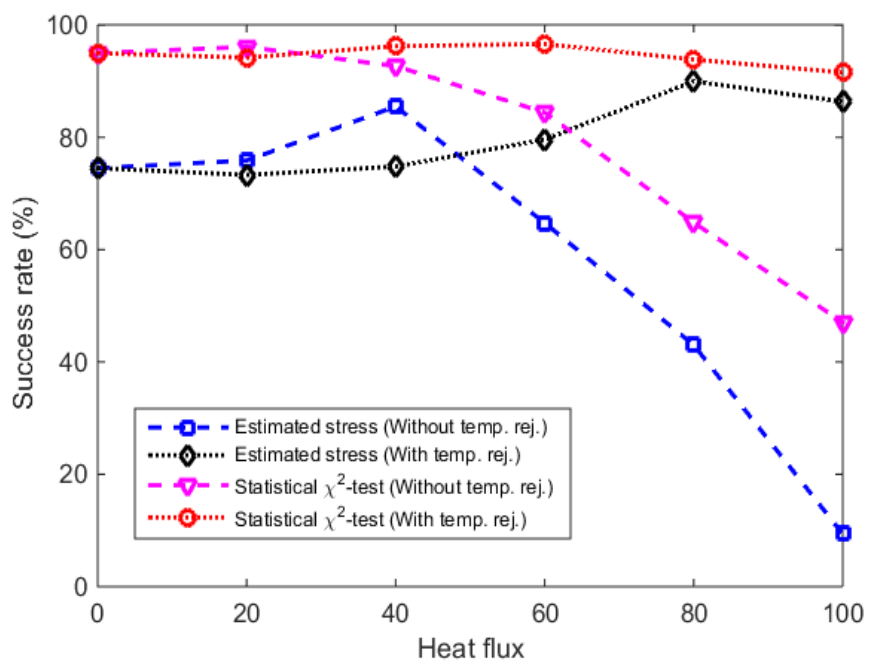

Figure 6. With/without temperature rejection: Success rates of damage localization for different heat flux. Damaged elements are 12,13 and 14 .

\section{CONCLUSIONS}

As basis, a review on relevant case studies and methods was conducted. The aim of the study is to classify the specific problems and to outline briefly SHM strategies for environmental based perturbations.

Secondly, a summary is given on the physical behavior of bridge structures and its components based on material testing. Better knowledge of material behavior affected by environmental conditions like temperature distribution and humidity is generally seen as crucial for assessment strategies for the loading bearing behavior of bridges.

On the common base of the stochastic subspacerelated system description three different methods for damage diagnosis are introduced. Especially the algorithm, where the reference null space and the residual covariance are based on an interpolation step shows promising results in eliminating environmental perturbations.

With the Stochastic Dynamic Damage Locating Vector (SDDLV) method another statistical approach is introduced. This vibrational damage localization method is based on a finite element model of a structure as well as output-only measurements in both reference and damaged states. In simulations the effect of the temperature rejection could be shown.

\section{REFERENCES}

Baeßler, M. \& Hille, F. (2018) A study on diverse strategies for discriminating environmental from damage based variations in monitoring data. IABMAS 2018. Melbourne, Australia.
Balmès, É., Basseville, M., Bourquin, F., Mevel, L., Nasser, H. \& Treyssède, F. (2008) Merging Sensor Data from Multiple Temperature Scenarios for Vibration Monitoring of Civil Structures. Structural Health Monitoring, 7, 129-142.

Bhuyan, M. D. H., Döhler, M., Lecieux, Y., Mevel, L. \& Schoefs, F. (2017) Statistical damage localization with stochastic load vectors using multiple mode sets. Structural Health Monitoring.

Döhler, M., Marin, L., Bernal, D. \& Mevel, L. (2013) Statistical decision making for damage localization with stochastic load vectors. Mechanical Systems and Signal Processing, 39, 426-440.

Döhler, M., Mevel, L. \& Hille, F. (2014) Subspace-based damage detection under changes in the ambient excitation statistics. Mechanical Systems and Signal Processing, 45, 207-224.

Eisenmann, J., Lempe, R. \& Steinbeisser, L. (1969) Beitrag zur Ermittlung der Werkstoffeigenschaften und des Verformungsverhaltens von bituminös gebundenen Straßendecken. Strassenbau und Verkehrstechnik, 81.

Farrar, C. R., Doebling, S. W., Cornwell, P. J. \& Straser, E. G. (1997) Variability of modal parameters measured on the Alamosa Canyon bridge. 15th International Modal Analysis Conference (IMACXV).

Fritzen, C. P., Mengelkamp, G. \& Güemes, A. (2003) Elimination of temperature effects on damage detec-tion within a smart structure concept. 4th International Workshop on Structural Health Monitoring Stanford, CA, USA.

Gautier, G., Mevel, L., Dumoulin, J., Döhler, M., Pen, M. L., Siegert, D. \& Merliot, E. (2018) An experimental setup for subspace based damage identification methods. European Geosciences Union, General Assembly. Vienna, Austria.

Gonzales, I., Ülker-Kaustell, M. \& Karoumi, R. (2013) Seasonal effects on the stiffness properties of a ballasted railway bridge. Engineering Structures, 57, 63-72.

Meruane, V. \& Heylen, W. (2012) Structural damage assessment under varying temperature conditions. Structural Health Monitoring, 11, 345-357.

Peeters, B. \& De Roeck, G. (2001) One-year monitoring of the Z24- Bridge: environmental effects versus damage events. Earthquake Engineering and Structural Dynamics, 30, 149171.

Rohrmann, R., Baeßler, M., Said, S., Schmid, W. \& Rücker, W. (2000) Structural Causes Of Temperature Affected Modal Data Of Civil Structures Obtained By Long Time Monitoring. XVIII. Int. Modal Analysis Conference (IMAC). San Antonio, TX, USA.

Simonsen, E., Janoo, V. C. \& Isacsson, U. (2002) Resilient properties of unbound road materials during seasonal frost conditions. Journal of Cold Regions Engineering, 16.

Viefhues, E., Döhler, M., Hille, F. \& Mevel, L. (2017) Stochastic subspace-based damage detection with uncertainty in the reference null space. 11th International Workshop on Structural Health Monitoring. Stanford, CA, USA.

Viefhues, E., Döhler, M., Zhang, Q., Hille, F. \& Mevel, L. (2019) Subspace-based Damage Detection with Rejection of the Temperature Effect and Uncertainty in the Reference. Submitted to 8th International Operational Modal Analysis Conference. Copenhagen, Danmark.

Welsch, J. (1984) Zentrischer Temperaturzwang von Stahlbeton und Spannbeton bei Abkühlung auf sehr niedrige Temperaturen. RU Bochum. 